\title{
CELEBRATING A DECADE OF PROGRESS AND PREPARING THE FUTURE THE SATELLITE PERSPECTIVE
}

\author{
G. Mark Doherty \\ ESA, ESRIN, Via Galileo Galilei,00044 Frascati, Italy, mark.doherty@esa.int
}

\begin{abstract}
Key achievements in satellite observation of the global oceans during the last decade are outlined. Challenges to be met in the coming decade are identified and issues pertinent to realizing the societal benefits of global ocean observations are considered.
\end{abstract}

\section{INTRODUCTION}

This paper draws upon the achievements of Earth Observation programmes that Space Agencies have been internationally coordinating via the Committee on Earth Observation Satellites (CEOS) during the last ten years. Although the discussion focuses on satellite observations, it is presented in the context of an integrated monitoring system, incorporating in-situ and satellite observations with models of the underlying physical, chemical and biogeochemical ocean processes. Progress on in-situ observations is discussed elsewhere.

\section{PROGRESS IN THE LAST DECADE}

Amongst the many considerable advances in satellite ocean observations during the past decade, the following can be considered as strategically important.

\subsection{Continuity in global ocean observations from space}

Long-term data continuity remains as the major stumbling block in the move from innovative researchdriven observations and application demonstrations to operational monitoring systems that can be sustained for decades. Data continuity is a pre-requisite for government agencies and industries - who are the primary agents of societal benefit - to rely on any observing system. From this perspective, the prime achievement of satellite ocean observation in the last decade has been to extend and improve observing capabilities that were already in place during the 1990s, and to maintain those that were launched subsequently. This has permitted existing operational users to remain engaged, and enabled decadal-scale, global time series of satellite ocean observations to be built up.

- Satellite observations of polar sea ice, initiated with the passive microwave SSMR/Nimbus (Scanning Multichannel Microwave Radiometer/Nimbus-7) (1978) and SSMI/DMSP (Special Sensor Microwave Imager /Defense Meteorological Satellite Program) (1987+) series, were continued for a third decade, and augmented by improved spatial resolution of AMSR-E/EOS
(Advanced Microwave Scanning Radiometer for EOS (Earth Observing System)-Aqua (2002+). High-resolution Synthetic Aperture Radar (SAR) imaging capabilities for tactical ice surveillance were expanded with the launch of the Advanced Synthetic Aperture Radar (ASAR) on ENVISAT (2002+) and RADARSAT-2 (2007+).

- Satellite observations of global sea surface temperature were extended for a further decade with high-temporal sampling data from geostationary orbits (GOES (Geostationary Operational Environmental Satellite), Meteosat), high-spatial resolution observations from polarorbit AVHRR/NOAA (Advanced Very High Resolution Radiometer/National Oceanic and Atmospheric Administration), (AVHRR/METOP (Meteorological Operational Satellite) (2006+), climate-quality observations with ATSR/ERS (Along-Track Scanning Radiometer / European Remote-sensing Satellite) (1991+), AATSR/ENVISAT (Advanced ATSR) (2002+), and all-weather coverage with AMSR-E/EOSAqua(2002+).

- Satellite observations of global ocean surface vector winds, initiated with AMI/ERS (Active Microwave Instrument) (1991, 1994+) were extended and improved with QuikSCAT/SeaWinds (Quick Scatterometer) (1999-2009), and reached operational status with ASCAT/METOP-A (Advanced Scatterometer/Meteorological Operational satelliteA) $(2006+)$.

- Satellite observations of global sea surface height by Radar Altimetry were extended for a further 10 years: high-precision observations from low-inclination orbit, initiated with TOPEX/Poseidon (NASA/CNES). (1992-2005) and GFO (GEOSAT Follow-On (Geodetic \& Oceanographic SATellite)) (1998-2008), were extended by Jason-1\&2 (2001+, 2008+). High inclination orbit observations initiated by RA/ERS1\&2 (Radar Altimeter) (1991-2000, 1995+) were extended by RA2/ENVISAT (2002+).

- Satellite observations of global sea state were maintained with significant wave height measurements from satellite Radar Altimeters, augmented by improved estimates of ocean swell characteristics from Satellite SAR imagery. 
- Satellite observations of global ocean colour entered a new era with continuity of SeaWiFS/Orbview-2 (Sea-viewing Wide Field-ofview Sensor) (1997+) and concurrent global observations from MODIS/Terra (ModerateResolution Imaging Spectroradiometer) (1999+), MODIS/Aqua (2002+) and MERIS/ENVISAT (Medium Resolution Imaging Spectrometer) (2002+).

- New satellite missions to initiate the first global observations of ocean surface salinity from space were developed for launch: SMOS (Soil Moisture Ocean Salinity) in 2009 and Aquarius in 2010.

This summary is non-exhaustive, listing only missions with global coverage, for brevity. A complete, up-todate database of all Earth Observation (EO) missions and sensors operated by CEOS agencies since 1990, including missions with regional coverage, and presenting planned timelines for future observations, is available on-line [1].

An assessment of the adequacy of global satellite ocean observations for climate [2], conducted in 2009, identified substantial improvements in space agencies' commitments to ocean surface observations since 2006. However, the adequacy of observations for several ocean variables, for which currently operating satellites have passed their planned lifetime or have no redundancy, was considered to be marginal.

\subsection{Major advances in ocean and climate science}

Data continuity, coupled with systematic improvements in spatial and temporal sampling, successive improvements in calibration and validation, improved retrieval methods, and innovative techniques for measuring new variables, has enabled significant advances in ocean and climate science during the last decade [3 and 4]. Major advances in monitoring and understanding the causes of global and regional trends in sea-level during recent years [5] has been made possible by improved inter-calibration, re-tracking, geophysical correction, and orbital estimation for satellite altimetry. The availability of decadal-scale global observations of ocean colour radiances from multiple satellites has opened new prospects for understanding variability in ocean bio-geochemical processes and ecosystems [6].

\subsection{A foundation for Earth System modelling}

Superior coverage, quality and accessibility of satellite ocean observations has underpinned major advances in developing and validating numerical models of the Earth system as a whole and of the ocean component in particular. These efforts, spearheaded by the Global Ocean Data Assimilation Experiment (GODAE) [7] and WCRP (World Climate Research Program) Climate Variability (CLIVAR) [8] projects have introduced powerful new data assimilation techniques [9], and significantly increased ocean forecasting skill [10], leading to directly traceable societal impacts.

\subsection{Operational services of benefit to society}

The marine sector is a major contributor to the global economy. Improved ocean observations and associated developments in data assimilation, modelling and forecasting capabilities during the last ten years have had direct beneficial impacts on key economic sectors such as maritime transport, fisheries, aquaculture, energy and tourism [10]. This is well illustrated by the new generation of global high-resolution sea surface temperature products [11], combining multiple satellite observations from infrared and passive microwave sensors with in-situ data, which provide improved inputs for Numerical Weather prediction.

The example of high-resolution ice charts, derived from all-weather space-borne SAR and in-situ observations, and delivered to Baltic-sea icebreakers [12] also demonstrates tangible societal benefits: more efficient energy use, reduced emissions, and safer shipping. As a result of government commitments to maintain and expand space-borne SAR systems in future, such existing services are now being expanded [13] to benefit additional users in the Canadian Arctic, Greenland, European Arctic, and Antarctic regions.

During the last decade, governments worldwide have made increasing use of satellite observations to support policy-making and regulation of the marine and coastal environments. In Europe, for example, most EU coastal states are integrating satellite ocean colour data into existing national water quality monitoring services as a cost-effective way to satisfy new regulatory monitoring obligations of the EU Water Framework Directive [14].

\subsection{Enlarged international cooperation}

Recent years have seen a progressive increase in the number of countries developing and operating satellites for ocean, terrestrial and meteorological observations. The ambitious long-term EO programmes of India, China and Brazil, have already placed significant new ocean-observing systems in orbit and will continue to expand in coming years. These new developments, along with the expanding capabilities of Europe, North America and Japan, open new prospects for international cooperation as a means to enhance the sustainability of a global ocean observing system.

\subsection{A political framework for global Earth Observation}

The international political consensus that led to the 10year implementation plan for the Global Earth Observing System of Systems (GEOSS) [15] represents a major step towards sustainability. GEOSS now provides a global framework within which autonomous 
Earth Observing systems (space-borne, sea-borne, terrestrial and air-borne) of different nations can be coordinated effectively at global level.

The last decade also saw an intense dialogue between space agencies and the international climate research community, conducted via CEOS (Committee on Earth Observing Satellites) and GCOS (Global Climate Observing System). This resulted in an authoritative statement of requirements for satellite-based observations of "Essential Climate Variables" [16] and a corresponding implementation plan from CEOS Agencies [17]. Both were unanimously endorsed by parties to the United Nations Framework Convention on Climate Change.

This new framework for coordinated global observations is founded on the recognition that no single nation will build the global observing system required by all. Rather, a comprehensive global earth observing system (of systems), serving the collective needs of all, can be established by coordinating the observing systems that individual nations and regions are building to meet their own geographically focused needs.

The progress made via the GCOS/CEOS plans demonstrates concretely that actions to improve observations for one societal benefit area also contribute significantly to other areas, thus substantiating the overarching objectives of GEOSS.

\section{CHALLENGES AND THE WAY FORWARD}

\subsection{Sustainability}

Notwithstanding this considerable progress, present and planned ocean (and Earth) observing satellite systems cannot yet be considered as fully sustainable. The continued existence of many systems relies on research and development funding which, by its nature, cannot ensure continuity on time-scales commensurate with operational needs.

When the life-cycle of satellite-based ocean observing systems is benchmarked against satellite meteorology, it is noted that sustainable funding arrangements were secured within 25 years of launch of the first geostationary weather satellites. Taking this timescale as reference, the goal of reaching sustainable funding for the more mature elements of the global ocean observing system in the next decade, can be considered realistic.

On the same timescale, it can also be foreseen that follow-on missions of a pre-operational nature will also be needed, to evolve and qualify new sensors (e.g. ocean salinity) before they can enter full operational use.

\subsection{Research and Operations: Transition and Balance}

The transition from research to operational status thus remains as a major milestone in the lifecycle of any new observing system [18] and continues to challenge space agencies. This issue has strongly influenced the strategy of national and international Earth Observation programmes throughout the last decade. It is central to the rationale of major new integrated observing programmes such as the Global Monitoring for Environment and Security (GMES) in Europe [19] and the International Earth Observing System (IEOS) in USA [20]. These programmes aim to incorporate new observing capabilities, previously validated with research missions, within a sustained long-term operational infrastructure.

Experience with previous EO systems shows this transition to be gradual and lengthy. Moreover, it requires balanced involvement of expertise, facilities, organizations, and funding, from research and operational communities, throughout the entire system life-cycle.

Operational users have a high interest to contribute actively to validating new observing systems. This enables them to gradually build confidence in 'research' observations, by cautiously introducing new data into their working environment. This is done despite the fact that the data availability and reliability does not fully satisfy 'operational' needs. This interaction between research and operational communities, centred on the evaluation of data from research missions in an operational context, is an essential step in the definition of comprehensive, stable requirements for future operational systems.

Previous experience also shows that this interaction remains essential even after the 'transition' to operations is achieved. The research community has a vital role to play in realizing the full benefits from investments made in operational observing systems. Improved processing algorithms significantly enhance the quality of operational data streams. Insights into the limits of in-orbit sensor performance lead to optimized satellite operations. Innovative data analysis methods open new fields of application and benefit additional user communities. Conversely, research communities increasingly require access to long-term time-series from operational observing systems, particularly in the climate and ocean sciences.

It is evident that, to be sustainable, global observing programmes must make explicit provision so that data 
from research and operational observing systems can be used jointly by research and operational communities. Institutional barriers that inhibit this must be overcome. Achieving balanced benefits for research and operational communities is thus a critical measure of cost-effectiveness for any future global observing system.

\subsection{Robustness}

A basic indicator of sustainability for any satellite observing system is its fault tolerance and robustness under foreseeable failure conditions. Such system-level robustness typically requires redundancy, at satellite, sensor, and component level.

In the most stringent cases, users with critical requirements (e.g. maritime security and surveillance), may require a capacity for immediate in-orbit replacement of one or more sensors or satellites.

The present global ocean observing system - 'under construction' - does not offer this degree of robustness. In practice, several user communities risk that the loss of a single satellite or sensor could disrupt observations of one or more ocean variables for an indefinite period.

Robustness in a coordinated global system, and back-up contingencies for national systems, can be achieved in a cost-effective way, through international cooperation. This is already established practice for meteorological satellites [21].

The CEOS 'virtual constellations' represent a concerted international effort to achieve system robustness for GEOSS. Space Agencies are pooling efforts to address this issue for six different classes of observation. Ocean observations are at the forefront of this initiative, as subject of three of the six virtual constellations: oceansurface topography [22]; Ocean surface vextor winds; and ocean colour radiometry [23].

\subsection{Climate science}

During the last decade, climate change has been recognized as one of the greatest challenges facing humanity in the coming century. Governments are confronted by decisions that have profound, enduring consequences for their nations' economies and their citizens' welfare and security. National and international policies to mitigate and adapt to dangerous climate change are informed by international scientific consensus, expressed via the IPCC (Intergovernmental Panel on Climate Change) [24]. The necessity for satellite-based global observations to support this process was re-affirmed at the UNFCCC COP15 (United Nations Framework Convention on Climate Change - Conference of the Parties), in Copenhagen in December 2009, which explicitly:

"Urges Parties that support space agencies involved in global observations to enable these agencies to continue to implement, in a coordinated manner through the Committee on Earth Observation Satellites, the actions identified in the updated report of the Committee on Earth Observation Satellites, in order to meet the relevant needs of the Convention, in particular by ensuring long-term continuity of observations and data availability. “

\subsection{Securing public funding}

The present generation of ocean observing satellites were developed to serve public needs, and thus are publicly funded. There is little evidence to suggest that this situation will change in the foreseeable future. Consequently, if an operational satellite infrastructure for systematic monitoring of the Earths' oceans, atmosphere, land and ice masses, serving public needs of all countries in the world, is to be realized, then dedicated long-term public funding must be secured.

The need for a global observing infrastructure and the funding implications, have been implicitly acknowledged by GEOSS member countries. In accordance, CEOS space agencies, supported by their governing authorities, are continuing to pursue ambitious multi-decade EO programmes, all with a significant ocean observing component, and all addressing public good. The overriding measure of success of these programmes is that they must, within an acceptable timeframe, enable societal benefits [25, 26 and 27] that justify their costs.

\subsection{Delivering societal benefits}

Societal benefits result from Earth Observations, not when satellites are launched or data is acquired, but when derived information is used to positively impact decisions of public consequence. This requires a multitude of value-adding processes to transform observed data into various types of information that policy makers and citizens - who are the ultimate beneficiaries - can readily access, understand and use. In practice, societal benefits are a consequence of wellinformed policies and decisions - both individual and collective - that are informed by observations and science. For this, data and information must be accessible.

\subsection{Data Access: full and open}

The last decade has seen increased recognition that data access is an essential condition for realizing the societal benefits of publicly funded satellite observations. Data access is a multiplier of societal benefits. Re-utilization of data for multiple purposes by multiple users increases cost-effectiveness. In contrast, impediments to data access limit opportunities for utilization and restrict the benefits, thereby diminishing cost-effectiveness and ultimately weakening the case for continued public support. 
Public sector users of EO data have repeatedly cited data access as a deciding factor for their utilization of satellite observations [28]. The GEOSS data-sharing principles [15], respond directly to this concern. They provide a global platform for realizing societal benefits, based on "full and open exchange" of data, meta-data and products. Within Europe, The European Space Agency (ESA) member states have followed this approach by approving a "full and open" data policy for the GMES Sentinel missions. Within the US, NOAA, pursuing the same principles is taking substantial measures to further improve access to its ocean and coastal data and products [29].

\section{CONCLUSION}

Satellite observations of the global oceans are poised to enter a new era of sustainability in the next decade. Governments are committed to long-term national, regional and global observing programmes that are conceived as a public good. A robust global earth observing system, based on data sharing and interoperable national and regional satellite systems, can be achieved through international cooperation. More direct, continuous interaction between operational and research communities will be needed to optimize system performance and cost-effectiveness. Building on their achievements in the last decade, the ocean observing community is in a position to pave the way for other components of the Global Earth Observing System of Systems.

\section{REFERENCES}

1) CEOS (2009): CEOS Mission, Instruments and Measurements Database online: http://database.eohandbook.com/

2) GCOS (2009): "Progress Report on implementation of the Global Observing System for Climate in support of the UNFCCC 2004-2008": GCOS-129 ,WMO TD/No. 1489, GOOS-173, GTOS-70.

3) . Busalacchi, A. (2010). "Celebrating a Decade of Progress and Preparing for the Future: Ocean Information for Research and Application" in these proceedings (Vol. 1), doi:10.5270/OceanObs09.pp.10.

4) Scott, R. \& Co-Authors (2010). "Satellite Altimetry and Key Observations: What We've Learned, and What's Possible with New Technologies" in these proceedings (Vol. 2), doi:10.5270/OceanObs09.cwp.76.

5) Cazenave, A. \& Co-Authors (2010). "Sea Level Rise Regional and Global Trends" in these proceedings (Vol. 1), doi:10.5270/OceanObs09.pp.11.

6) Yoder, J. (2010). "Ocean Colour Radiometry: Early Successes and a Look Towards the Future" in these proceedings (Vol. 1), doi:10.5270/OceanObs09.pp.43.

7) Wilson, S. \& Co-Authors (2008). "Satellite observing systems and relevance to GODAE" in final GODAE symposium, proceedings.
8) Cattle, H. (2010). "WCRP CLIVAR and Ocean Observations" in these proceedings (Annex).

9) Rienecker, M. \& Co-Authors (2010). "Synthesis and Assimilation Systems - Essential Adjuncts to the Global Ocean Observing System" in these proceedings (Vol. 1), doi:10.5270/OceanObs09.pp.31.

10) Le Traon, P., Bell, M., Dombrowsky, E., Schiller, A. and Wilmer Becker, K. (2010)."GODAE OceanView: From an Experiment Towards a Long-Term International Ocean Analysis and Forecasting Program" in these proceedings (Vol. 2), doi:10.5270/OceanObs09.cwp.57.

11) Donlon, C. \& Co-Authors (2010). "Successes and Challenges for the Modern Sea Surface Temperature Observing System" in these proceedings (Vol. 2), doi:10.5270/OceanObs09.cwp.24.

12) Karvonen, A. et al., (2007). "Baltic Sea Ice Thickness Charts Based on Thermodynamic Ice Model and SAR Data": Proc of the International Geoscience and Remote Sensing Symposium 2008 (IGARSS'08), 2008.

13) Breivik, L. \& Co-Authors (2010). "Remote Sensing of Sea Ice" in these proceedings (Vol. 2), doi:10.5270/OceanObs09.cwp.11.

14) Brockmann, C. et al. (2008). "Routine water quality services for the Baltic Sea (GMES MarCoast)": US/EUBaltic International Symposium, 2008 IEEE/OES. 27/06/2008; doi:10.1109/BALTIC.2008.4625541

15) GEO (2005): 10-Year Implementation Plan Reference Document: GEO 1000R February 2005. http://www.earthobservations.org/documents/10Year\%20Plan\%20Reference\%20Document.pdf

16) GCOS (2006): Systematic Observation Requirements for Satellite-based Products for Climate, GCOS-107, September 2006

http://www.wmo.int/pages/prog/gcos/Publications/gcos107.pdf

17) CEOS (2006): Satellite Observation of the Climate System - The Committee on Earth Observation Satellites (CEOS) Response to the Implementation Plan for the Global Observing System for Climate in Support of the UNFCCC, October 2006. http://www.ceos.org/pages/CEOSResponse_1010A.pdf

18) Ratier, A. (1999). "Space-based observations in the Global Observing System: The operational transition issue" OceanObs 1999.

19) Commission of the European Communities (2008): "Global Monitoring of Environment and Security: we care for a safer planet". COM (2008) 748 final

20) CENR/IWGEO.2005. Strategic Plan for the U.S. Integrated Earth Observation System. National Science and Technology Council Committee on Environment and Natural Resources, Washington, DC.

21) NOAA (1997)."Geostationary Satellite Acquisition Strategy Improved, but Store-in-Orbit approach needs re-evaluation": Inspection Report No OSE-8784-70001/March 1997. 
22) Wilson, S. \& Co-Authors (2010). "The Ocean Surface Topography Constellation: The Next 15 Years in Satellite Altimetry" in these proceedings (Vol. 2), doi:10.5270/OceanObs09.cwp.92.

23) Yoder, J., Dowell, M., Hoepffner, N., Murakami, H. and Stuart, V., (2010). "The Ocean Colour Radiance Virtual Constellation (OCR-VC)." in these proceedings (Vol. 2), doi:10.5270/OceanObs09.cwp.96.

24) Trenberth, K. \& Co-Authors (2010). "Intergovernmental Panel for Climate Change (IPCC) and Attribution and Prediction of Climate: Progress since the Fourth Assessment" in these proceedings (Vol. 1), doi:10.5270/OceanObs09.pp.39.

25) PriceWaterhouseCoopers (2006): "Main Report SocioEconomic Benefits Analysis of GMES": ESA Contract number 18868/05

http://esamultimedia.esa.int/docs/GMES/261006_GMES D10 final.pdf

26) Leveson, I., (2008): NPOESS Economic Benefits, Prepared for the NPOESS Integrated Program Office, Leveson Consulting, June, 2008.

27) NOAA.(2009). "NOAA Integrated Ocean Observing System (IOOS) Program: Strategic Plan 2008-2014.

28) European Environment Agency (2009). "A global setting for European environmental monitoring - measuring what we must manage. EEA International conference, 13-15 May 2009. Key conclusions.": EEA Corporate document No 4/2009.

29) NOAA (2009)."The Business case for improving NOAAs management and integration of Ocean and Coastal Data". 